Article

\title{
Experiments on Waste Heat Thermoelectric Generation for Passenger Vehicles
}

\author{
Jianfei Chen ${ }^{1,2}$, Wei Xie ${ }^{1,2}$, Min Dai ${ }^{1}$, Guorong Shen ${ }^{1}$, Guoneng $\mathrm{Li}^{2, *}$ and Yuanjun Tang ${ }^{2}$ \\ 1 Zheneng Intelligent Energy and Technology Industrial Park, Huzhou 313100, China; cjf661121@163.com (J.C.); \\ xiewei@zhenergy.com.cn (W.X.); dm13355828192@163.com (M.D.); staffshen2022@163.com (G.S.) \\ 2 Department of Energy and Environment System Engineering, Zhejiang University of Science and Technology, \\ Hangzhou 310023, China; 119037@zust.edu.cn \\ * Correspondence: 109026@zust.edu.cn; Tel.: +86-571-85070216
}

Citation: Chen, J.; Xie, W.; Dai, M.; Shen, G.; Li, G.; Tang, Y. Experiments on Waste Heat Thermoelectric Generation for Passenger Vehicles. Micromachines 2022, 13, 107 https://doi.org/10.3390/mi13010107

Academic Editor: Mercè Pacios

Received: 9 December 2021

Accepted: 5 January 2022

Published: 10 January 2022

Publisher's Note: MDPI stays neutral with regard to jurisdictional claims in published maps and institutional affiliations.

Copyright: (C) 2022 by the authors. Licensee MDPI, Basel, Switzerland. This article is an open access article distributed under the terms and conditions of the Creative Commons Attribution (CC BY) license (https:// creativecommons.org/licenses/by/ $4.0 /)$.

\begin{abstract}
In order to utilize waste heat from passenger vehicles by a thermoelectric generator (TEG), a lab-scale TEG with a sufficient low-pressure drop was designed and tested. The waste heat from a 2.0 L petrol engine was simulated by using an air-circulation channel with an adjustable electric heater and a speed control motor. The TEG consisted of an integrated molding designed aluminum-finned heat collector, twenty thermoelectric modules, and a set of water-cooled heat sinks. Experiments were conducted in terms of power load feature, pressure drop, heat collection efficiency, thermoelectric efficiency and overall efficiency. It was found that the hot-end temperature was much lower (46.9\%) than the flue gas temperature because the trade-off between fin area and pressure drop had to be considered. The obtained maximum electric power was $36.4 \mathrm{~W}$, and the corresponding pressure drop was $36 \mathrm{~Pa}$. The corresponding heat collection efficiency was $46.5 \%$, and the thermoelectric efficiency was $2.88 \%$, which agreed well with the theoretical prediction of $3.38 \%$. As a result, an overall efficiency of $1.21 \%$ was reached. The present work firstly demonstrated a waste-heat-recovering TEG prototype with a balanced overall efficiency of over $1 \%$, and a pressure drop of less than $50 \mathrm{~Pa}$. On the other hand, the maximum electric power was difficult to fully extract. The charging power to a battery with a maximum power point tracking direct current-direct current converter was experimentally verified to work at a much higher conversion efficiency $(15.3 \%$ higher) than regular converters.
\end{abstract}

Keywords: waste heat recovery; thermoelectric generator; heat collection efficiency; overall efficiency; pressure drop

\section{Introduction}

Nowadays, the recovery of waste heat for industrial conversion into electricity is among the major challenges facing humanity. A thermoelectric generator (TEG) is one of the promising candidates. The working principle of a TEG is the Seebeck effect, which directly converts temperature difference into electricity in a solid state. Owing to great advances of TE materials in recent years, TEGs with a high efficiency are expected to emerge in the near future. For example, SnSe has a figure-of-merit (ZT) value of 2.6 in hightemperature zones [1], and further improvements found that the $Z T$ value could reach 1.34 in low-temperature zones [2]. Therefore, TEG has been studied in many applications. These applications include electricity generation in space exploration and in remote areas [3], waste heat recovery in automobiles, aircrafts, ships and industrial flue gas pipelines [4] and micro TEGs [5]. A brief literature review, focusing on recent TEG studies utilizing waste heat from passenger vehicles is provided, as follows.

Remeli et al. [4] proposed a concept of combined heat recovery and power generation using a heat-pipe-assisted TEG. Although the measured TE efficiency of $0.7 \%$ was relatively low, a heat exchanger effectiveness of $41 \%$ was reached. Kim, Negash and Cho [6] designed a direct contact TEG in order to remove the contact resistance between the TE modules and 
the heat resource. The electric power per TE module was $1.08 \mathrm{~W}$. Li et al. [7] filled foam metals in the flue gas channel, aiming to improve the TEG performance, and the electric power per TE module was $2.75 \mathrm{~W}$. However, the pressure drop was found to be considerable (10,000 Pa). Kim, Kwak and Kim [8] developed a hexagonal-shaped TEG for passenger vehicle applications, where a total of $18 \mathrm{TE}$ modules were installed. The electric power per TE module was $5.44 \mathrm{~W}$. These results were obtained when the hot-end temperature was $336{ }^{\circ} \mathrm{C}$. The heat collection efficiency was measured to vary between $18 \%$ and $32.9 \%$, and the pressure drop was between $400 \mathrm{~Pa}$ and $2000 \mathrm{~Pa}$. A dynamic model of automobile TEG was developed by Lan et al. [9]. Numerical results revealed that a $20 \%$ average power output increase can be expected by optimizing the thermal contact conductance and the heat transfer coefficient of the heat collector. Massaguer et al. [10] performed detailed numerical investigations on an automobile TEG. They found that the maximum fuel economy value was only $0.18 \%$ with their TEG. The TEG performance utilizing flue gases and humidified flue gases were analyzed and compared using energy and exergy analysis by Zhao et al. [11]. Results found that the largest exergy destruction had different patterns for these two scenarios. Eddine et al. [12] found that the optimum clamping pressure for the TEG device was $0.35 \mathrm{MPa}$ in their test-rig, which simulated the heat recovery of a marine engine. The measured TE efficiency varied between $0.26 \%$ and $0.4 \%$. Zhao et al. [13] proposed a media-based TEG, and numerical results found that there was an optimal module area to maximize the output power when the exhaust heat exchange area was fixed. Marvão, Coelho and Rodrigues [14] proposed a gradient-based search method to optimize the fin structure inside a TEG for waste heat recovery in heavy-duty vehicles. Numerical results found that the thickness of the fins, wall ducts, electrical conductors and ceramic strips should be as small as possible. Recently, Tang et al. [15] developed a new type of high temperature heat pipe to assist TEG application, and experimental results found that the developed heat pipe was a promising method to improve the overall efficiency of the TEG. Brito et al. [16] applied phase change material to stabilize the hot-end temperature of the TEG, and solve the by-pass problem during high thermal-load events.

As revealed from the above analysis, recent studies have considerably augmented heat collection efficiency by installing foam metals into the gas channels [7], or increasing the gas velocity [8]. However, critical pressure drops, for example, $10 \mathrm{kPa}$ [7] and $0.4 \sim 2 \mathrm{kPa}$ [8], have been caused which, in return, lead to the performance degradation of the engine. Hence, further studies on automobile TEG are needed, particularly those focusing on the trade-off between the heat collection and pressure drop. In the present work, a new automobile TEG with a sufficient low-pressure drop, and attractive heat collection efficiency, was designed and tested. The gas flow rate in the present work was designed in accordance with a $2.0 \mathrm{~L}$ engine. Experiments were conducted in terms of power load features, pressure drop, heat collection efficiency, TE efficiency and overall efficiency. The obtained results showed that a minor pressure drop can be achieved while maintaining relatively large TE efficiency and overall efficiency. The contribution of the present work is to provide new experiment data and analysis in TEG applications with sufficient low-pressure drop.

\section{Materials and Methods}

\subsection{Experimental Setup}

The schematic of the experimental setup is shown in Figure 1. The TEG system consisted of a square aluminum-finned heat collector, twenty TE modules, four water-cooled heat sinks, a water tank, a water pump and a heat radiator with blowers. The heat collector was mounted directly to the exit of the electric heater as part of the circulation channel. Dimensions of the heat collector were $450 \mathrm{~mm}$ [length] $\times 77 \mathrm{~mm}$ [inner width] $\times 77 \mathrm{~mm}$ [inner height], and 12 flat-plate fins with a thickness of $2.5 \mathrm{~mm}$ were designed. The distribution of the abovementioned fins adhered to the following procedures: (1) a cylinder-shaped hollow zone with a diameter of $38 \mathrm{~mm}$ was deliberately left, which acted as the bypass channel; (2) eight fins (four on each side) on two opposite sides of the inner wall of the heat collector were integrated, four fins were measured with a height of $16 \mathrm{~mm}$, and the height of the 
other four fins was $23 \mathrm{~mm}$; (3) four fins (two on each side) with a height of $19 \mathrm{~mm}$ on the other two opposite sides of the inner wall of the heat collector were arranged. A speed control motor was installed upstream of the electric heater, providing the forcing power of the air flow, and a variable frequency drive was used to adjust the motor speed. The heating power varied between $1 \mathrm{~kW}$ and $3 \mathrm{~kW}$. The air velocity varied between $2.06 \mathrm{~m} / \mathrm{s}$ and $8.11 \mathrm{~m} / \mathrm{s}$, which was measured with a Testo hot-wire velocimeter $405 \mathrm{i}$ with an accuracy of 5\%. An infrared imager Dali T8 was used to capture the temperature distribution of the TEG system. A differential pressure transducer CHY-130 was installed to measure the pressure drop of the heat collector. The resolution of the thermal imager was $25 \mu \mathrm{m}$, and the accuracy of the differential pressure transducer was $0.5 \%$.
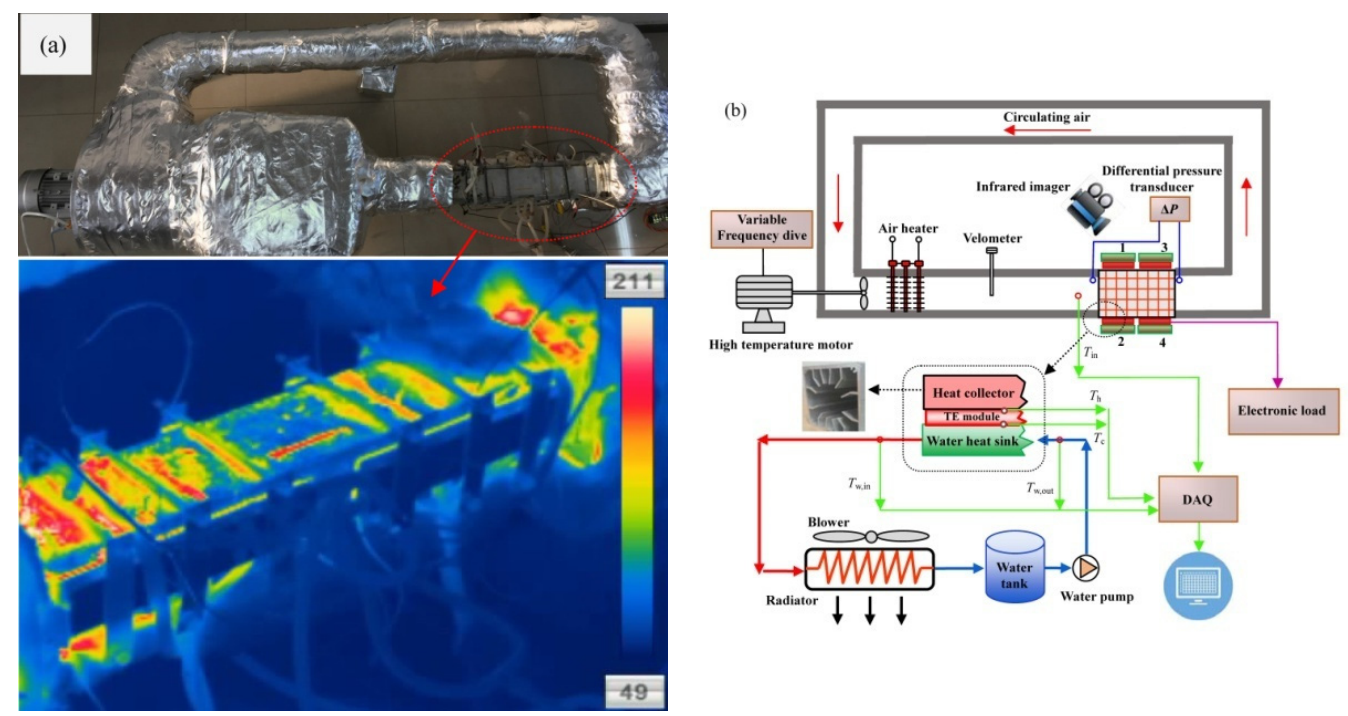

Figure 1. Experimental setup. (a) Photograph and thermal image of the TEG system. (b) Schematic of working principle and measuring system.

A commercially available $\mathrm{Bi}_{2} \mathrm{Te}_{3}$-based TE module, type "TEP1-126T200", with dimensions of $40 \mathrm{~mm}$ [length] $\times 40 \mathrm{~mm}$ [width] $\times 3.3 \mathrm{~mm}$ [thickness], was employed in the present TEG. According to the datasheet from the manufacturer, the internal electrical resistance of the TE module was $3.4 \Omega$, and the long-term working temperature was $200{ }^{\circ} \mathrm{C}$. The TE efficiency was $4.9 \%$ under the conditions of hot-/cold-end temperatures of $200{ }^{\circ} \mathrm{C}$ and $30{ }^{\circ} \mathrm{C}$, respectively. The height and cross-sectional area of the TE leg were $1.5 \mathrm{~mm}$ and $1.3 \mathrm{~mm} \times 1.3 \mathrm{~mm}$, and the thickness of the ceramic plate was $0.9 \mathrm{~mm}$. Meanwhile, various physical properties were also provided from the manufacturers to predict the TE efficiency theoretically. Four heat sinks with dimensions of $200 \mathrm{~mm}$ [length] $\times 40 \mathrm{~mm}$ [width] $\times 11.8 \mathrm{~mm}$ [thickness] were used to cool down the coldend of the TE module. A circular water channel with a diameter of $6 \mathrm{~mm}$ was designed inside the heat sink. The water channel was equidistantly distributed in an $\mathrm{M}$ shape, and the length of the four parallel sub-channels were $180 \mathrm{~mm}$. Four identical groups of TE module were installed in two opposite sides (with dense fins) of the heat collector, which is shown in Figure 1b. Group-1 and Group-2 were placed upstream of Group-3 and Group-4, respectively. The only difference between Group-1 (Group-3) and Group-2 (Group-4) was the measuring holes for the differential pressure transducer. In other words, two pressure measuring holes were designed ahead of Group-1 and behind of Group-3, respectively. Five TE modules were installed in each group. Therefore, a total of twenty TE modules were installed. In the present work, the output voltage of TEG was designed for batteries with a rated voltage of $24 \mathrm{~V}$. Hence, ten TE modules in each side of the heat collector were wired in series, and two sides were wired in parallel. Thus, the open circuit voltage of the TEG could be larger than $50 \mathrm{~V}$, which helped to extract as much electric power as possible during battery charging. 
Eleven type-K thermocouples were installed to measure the inlet air temperature, hot-end temperatures, cold-end temperatures, inlet water temperature and outlet water temperature, respectively. The accuracy of the thermocouples was $0.5 \%$, and an Agilent34970A data-acquisition (DAQ) instrument was used to record the temperature signals. The hot-/cold-end temperatures are measured with type-K patch thermocouples, which had a sufficient large contact area to compensate the thermal-conduction-induced measuring errors. Several "ears" were integrally molded with the heat collector and heat sink, providing installation locations for the abovementioned patch thermocouples. Furthermore, the abovementioned patch thermocouples were fastened with aluminum rivets. The errors caused by the thermal resistance of "ears" were taken into consideration when measuring hot-/cold-end temperatures. A Prodigit 3311F electronic load was used to explore the power load feature, and its accuracy was $0.5 \%$. In order to compare the performance of different kinds of DC-DC converters (DDCs), two regular DDCs, type ZS-Q5, and type DKP6012, and one maximum power point tracking (MPPT) DDC, type YF-BKT80V15A, were used.

The atmosphere and inlet water temperatures during experiments were $22^{\circ} \mathrm{C}$ and $19{ }^{\circ} \mathrm{C}$, respectively. Three heating powers, i.e., $1 \mathrm{~kW}, 2 \mathrm{~kW}$ and $3 \mathrm{~kW}$, and four flue gas velocities, i.e., $2.06 \mathrm{~m} / \mathrm{s}, 4.73 \mathrm{~m} / \mathrm{s}, 6.48 \mathrm{~m} / \mathrm{s}$ and $8.11 \mathrm{~m} / \mathrm{s}$, were selected in the experiments. Therefore, 12 running conditions were chosen, and 15 load resistances were explored for each running condition. As a result, a total of 180 experimental cases were conducted. The working conditions for water pump and the heat radiator remained unchanged during experiments. The heat flux entering into the heat collector was obtained by an electric kilowatt-hour meter on the basis of neglecting the heat dissipation from the outer surface of the channel between the electrical heater and the heat collector. The neglect of heat dissipation was reasonable, because insulations were applied and the distance between the electrical heater and heat collector was limited. This was confirmed by the thermal image, as shown in Figure 1. No obvious high temperature zones were found with the infrared imager, except the testing TEG. The electric kilowatt-hour meter was provided by the state grid Co., Ltd., and the accuracy was $0.1 \%$.

\subsection{Data Reduction}

Only part of the heat in the flue gases can be extracted by the heat collector. Therefore, the heat collection efficiency is defined as:

$$
\eta_{\text {heat }}=\frac{Q_{\mathrm{HC}}}{P_{\text {in }}}
$$

where $P_{\text {in }}$ is the heating power, which represents the heat flux of flue gases entering into the heat collector. $Q_{\mathrm{HC}}$ denotes the heat flow rate extracted by the heat collector. Furthermore, only partial $Q_{\mathrm{HC}}$ was responsible for power generation by TE modules, while others were dissipated by convection and radiation. The actual heat flux extracted by TE modules, $Q_{\mathrm{TE}}$, can be obtained as follows:

$$
Q_{\mathrm{TE}}=Q_{\mathrm{HC}}-Q_{\mathrm{conv}}-Q_{\mathrm{rad}}
$$

where $Q_{\text {conv }}$, and $Q_{\text {rad }}$ are the heat loss rates by convection and thermal radiation, respectively. Therefore, the effective heat collection efficiency can be defined as follows:

$$
\eta_{\text {heat,eff }}=\frac{Q_{\mathrm{TE}}}{P_{\text {in }}}
$$

TE modules converse directly part of $Q_{\mathrm{TE}}$ to electricity. Therefore, TE efficiency and overall efficiency can be defined as follows:

$$
\eta_{\mathrm{TE}}=\frac{P_{\max }}{Q_{\mathrm{TE}}}
$$




$$
\eta_{\text {sys }}=\frac{P_{\max }}{P_{\text {in }}}
$$

where $P_{\max }$ is the obtained maximum electric power. Hence, the TE efficiency must be larger than the overall efficiency, and satisfy the following equation.

$$
\eta_{\text {sys }}=\eta_{\text {heat,eff }} \eta_{\mathrm{TE}}
$$

The TE efficiency can be predicted theoretically with the following equation [17]:

$$
\eta_{\mathrm{TE}}=\frac{T_{\mathrm{h}}-T_{\mathrm{c}}}{T_{\mathrm{h}}}\left\{(1+2 r w)^{2}\left[2-0.5\left(\frac{T_{\mathrm{h}}-T_{\mathrm{c}}}{T_{\mathrm{h}}}\right)+\left(\frac{4}{Z T_{\mathrm{h}}}\right)\left(\frac{1+n / L}{1+2 r w}\right)\right]\right\}^{-1}
$$

where $T_{\mathrm{h}}$ is the hot-end temperature, and $T_{\mathrm{c}}$ denotes the cold-end temperature. The TE efficiency is mainly controlled by the figure-of-merit $(Z)$, which is defined as follows [18]:

$$
Z=\frac{\alpha^{2}}{k \rho}
$$

where $\alpha, \rho$ and $k$ are the Seebeck coefficient, electrical resistivity and thermal conductivity, respectively. $r$ and $w$ are the thermal contact ratio and the dimensional ratio of TE module, respectively. $n$ denotes the electrical resistivity ratio. For the present study, $w=0.516$. $r=0.2, n=0.1$ [18]. $L$ is the TE leg length, and $L=1.5 \mathrm{~mm}$. The $Z T_{\text {ave }}$ value in the present experimental cases varied between 0.80 and 0.85 .

\section{Results and Discussions}

\subsection{Temperature}

Figure 2 presents the inlet air temperature of the heat collector under various heating powers and air velocities. The air temperature was considerably high, even at the heating power of $1 \mathrm{~kW}$, which was benefited by the design of the air-circulation channel. The slightly decreasing trend of inlet air temperature as the air velocity increased was caused by the enhancement of convective heat transfer between the flowing air and channel walls. The average inlet air temperatures were $133^{\circ} \mathrm{C}, 236^{\circ} \mathrm{C}$ and $307^{\circ} \mathrm{C}$ for the heating power of $1 \mathrm{~kW}, 2 \mathrm{~kW}$ and $3 \mathrm{~kW}$, respectively, and the corresponding differences due to the air velocity were $11^{\circ} \mathrm{C}, 28^{\circ} \mathrm{C}$ and $29^{\circ} \mathrm{C}$, respectively. The flue gas temperature at the exit of the engine can be higher than $300^{\circ} \mathrm{C}$ [6]. However, the installation of a three-way-catalytic-converter and a muffler between the TEG and the engine can considerably decrease the flue gas temperature. Moreover, the contamination of fins in real applications will increase the heat transfer thermal resistance between the flue gas and heat collector. Thus, developing TEGs that work in clean flue gases with a flue gas temperature of approximately $300{ }^{\circ} \mathrm{C}$ is appropriate. The distance between the electric heater and the heat collector was short, compared with the whole length of the channel. Therefore, the input power to the heat collector was assumed to be the electric heating power. In other words, the input power to the heat collector was assumed to be $1 \mathrm{~kW}, 2 \mathrm{~kW}$ and $3 \mathrm{~kW}$, respectively.

The hot-end temperatures and corresponding temperature differences of different groups of TE modules under various heating powers and air velocities were shown in Figures 3 and 4. As shown in Figure 3, the hot-end temperature increased slightly with the air velocity, which was also caused by the enhanced convective heat transfer between the flowing air and the heat collector. It was interesting to found that the hot-end temperatures were quite different for Group-1 and Group-2, whereas the hot-end temperatures for Group-3 and Group-4 were close to each other. A possible reason for this phenomenon was the uneven flow field, due to the elbow upstream of the heat collector, which was shown in Figure 1. An important finding was the difference between the hot-end temperature and the inlet air temperature, i.e., the hot-end temperatures were considerably lower than the inlet air temperature. The average hot-end temperatures were $76.9{ }^{\circ} \mathrm{C}, 121.3^{\circ} \mathrm{C}$ and $151.6^{\circ} \mathrm{C}$ for the heating power of $1 \mathrm{~kW}, 2 \mathrm{~kW}$ and $3 \mathrm{~kW}$, respectively. This implied that 
an average temperature decreases of $108.7^{\circ} \mathrm{C}$ was found from flue gas temperatures to hot-end temperatures. Advanced methods, such as thermosyphon cooling [19], could be helpful to narrow the abovementioned gap. As a result, an essential problem of applying TEG to recover waste heat from flue gases should be the heat collection technology. A possible method to increase the hot-end temperature under a specific flue gas temperature is to increase the fin density. However, this is subject to the pressure drop problem, which will be discussed in Section 3.5. Balancing the heat collection efficiency and pressure drop is one of the major tasks in developing TEGs to utilize waste heat from engines.

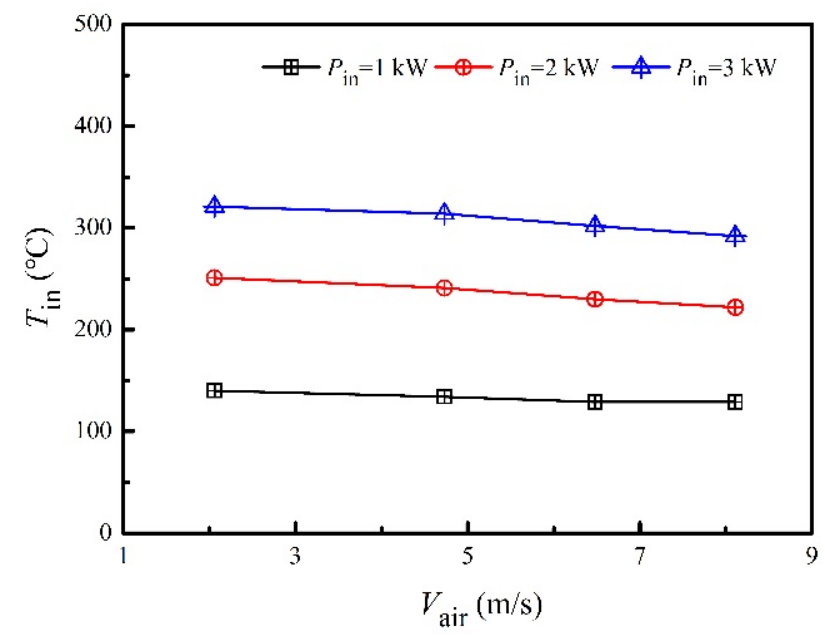

Figure 2. Inlet air temperatures of the heat collector under various heating powers and air velocities.
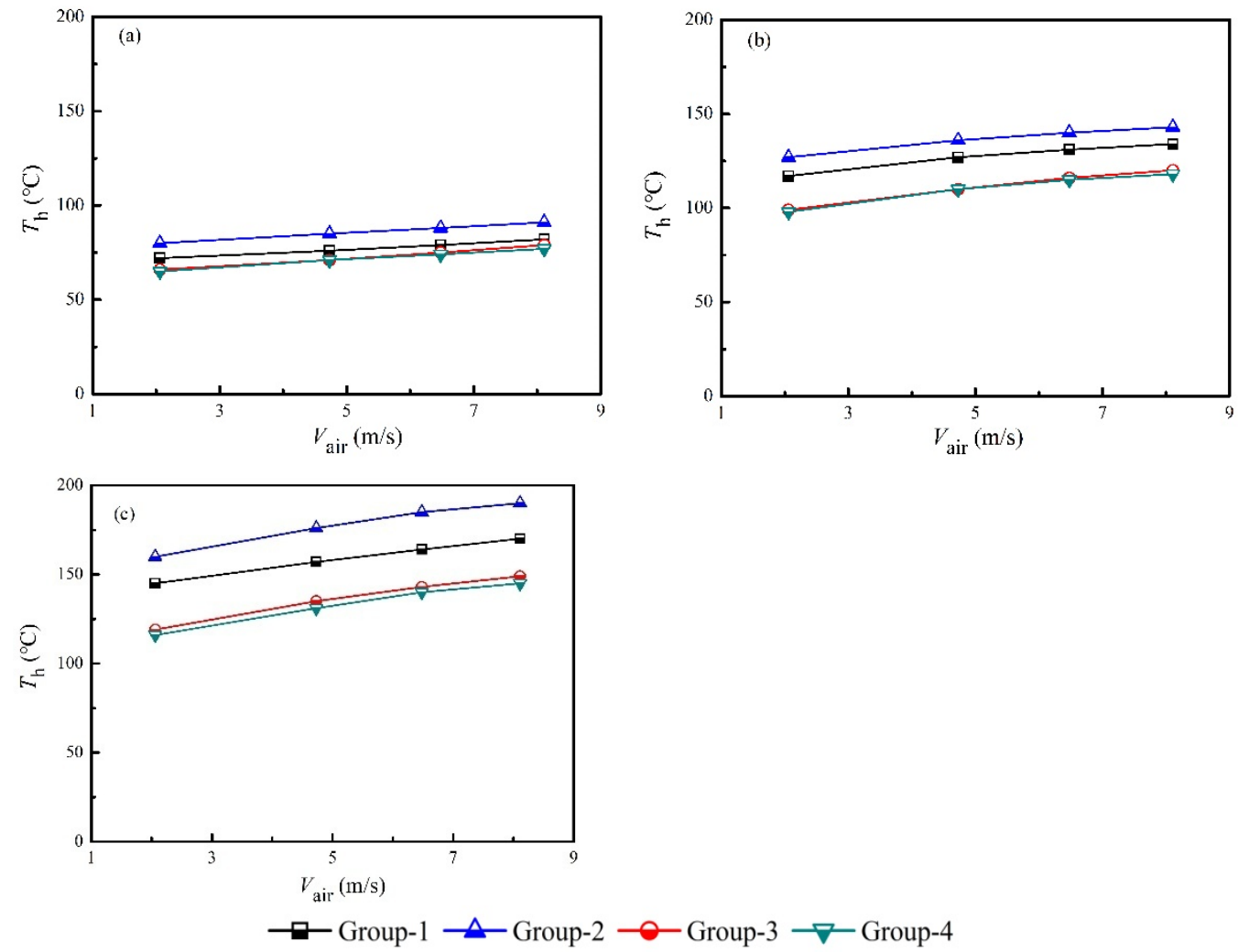

Figure 3. Hot-end temperatures of different groups under various heating powers and air velocities. (a) $P_{\text {in }}=1 \mathrm{~kW}$. (b) $P_{\text {in }}=2 \mathrm{~kW}$. (c) $P_{\text {in }}=3 \mathrm{~kW}$. 

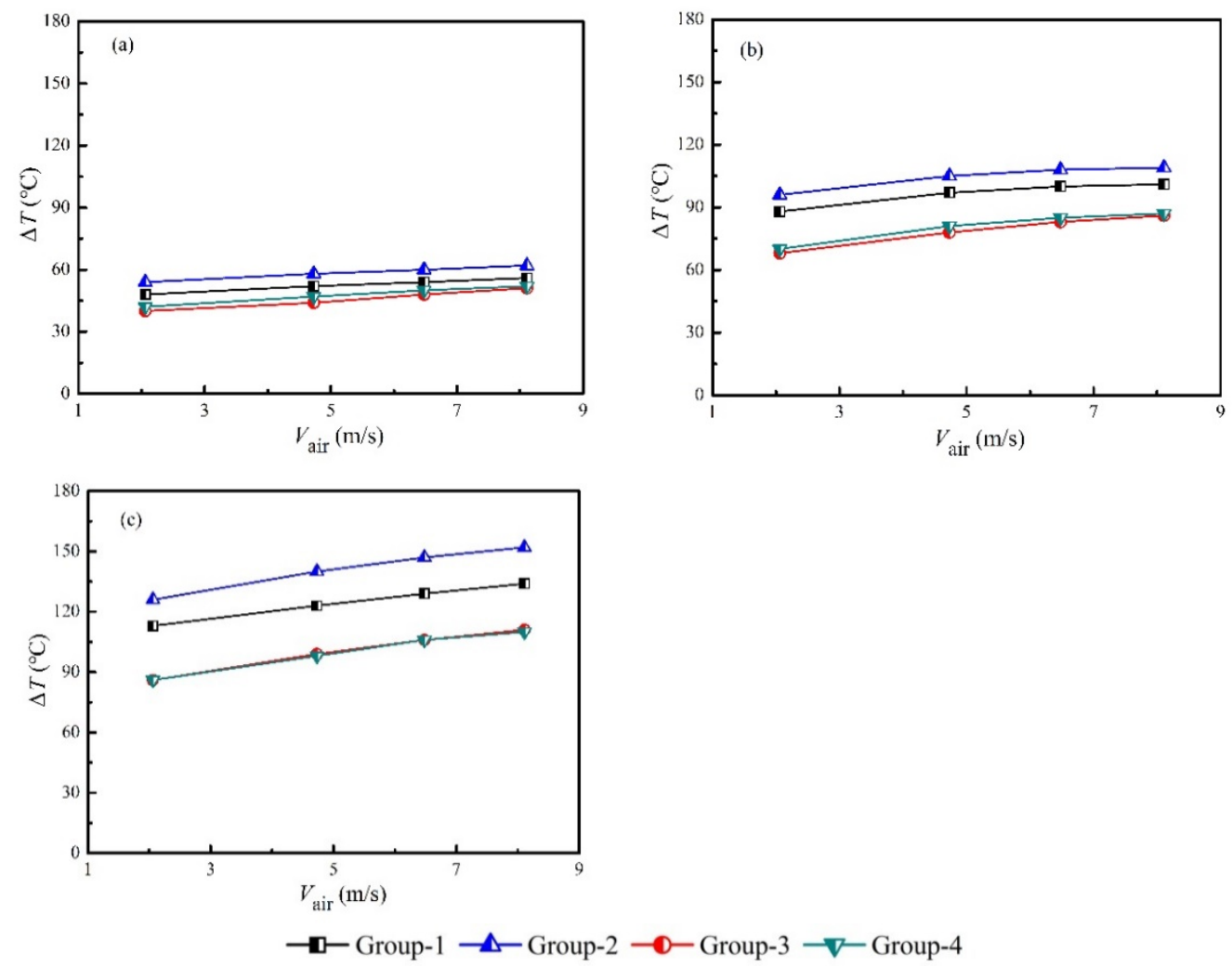

Figure 4. Temperature differences of different groups under various heating powers and air velocities. (a) $P_{\text {in }}=1 \mathrm{~kW}$. (b) $P_{\text {in }}=2 \mathrm{~kW}$. (c) $P_{\text {in }}=3 \mathrm{~kW}$.

The temperature differences increased with the heating power and air velocity, which was shown in Figure 4. The average temperature differences were $51.1{ }^{\circ} \mathrm{C}, 90.1{ }^{\circ} \mathrm{C}$ and $116.6^{\circ} \mathrm{C}$ when the heating power was set at $1 \mathrm{~kW}, 2 \mathrm{~kW}$ and $3 \mathrm{~kW}$, respectively. The corresponding differences due to the air velocities and different groups were $12.8^{\circ} \mathrm{C}$, $25.8^{\circ} \mathrm{C}$ and $42.25^{\circ} \mathrm{C}$, respectively. Therefore, obvious differences of electric power output were expected, which will be discussed in Section 3.2.

\subsection{Power Load Feature}

The electric powers generated by the TEG system at different load resistances under various heating powers and air velocities were shown in Figure 5. Air velocity was important in the augmentation of electric power output under a fixed heating power. For example, the maximum electric power at $8.11 \mathrm{~m} / \mathrm{s}$ was $36.4 \mathrm{~W}$ at $P_{\text {in }}=3 \mathrm{~kW}$. However, the maximum electric power was only $26.6 \mathrm{~W}$ at $2.06 \mathrm{~m} / \mathrm{s}$, under the same heating power, which means that a $26.9 \%$ of downgrade was reached. On the other hand, power load tests showed that the optimized load resistance was located at $20 \Omega$, indicating that the internal resistance of each TE module was $4 \Omega$. This was slightly larger than the data $(3.6 \Omega$ ) provided by the manufacture, which was caused by the increased temperature compared with the room temperature. The maximum electric powers were $8.6 \mathrm{~W}, 24.5 \mathrm{~W}$ and $36.4 \mathrm{~W}$ when the heating power was set at $1 \mathrm{~kW}, 2 \mathrm{~kW}$ and $3 \mathrm{~kW}$, respectively. This implies that the inlet air temperature was another important parameter for the power generation of the TEG system. In order to increase the electric power output, both the temperature and the velocity of the flue gases should be as large as possible. However, these two parameters cannot be optimized in waste heat recovery applications because they are boundary conditions. The power generation densities were $268.7 \mathrm{~W} / \mathrm{m}^{2}, 765.6 \mathrm{~W} / \mathrm{m}^{2}$ and $1137.5 \mathrm{~W} / \mathrm{m}^{2}$ based on the area of the TE modules when the heating power was set at $1 \mathrm{~kW}, 2 \mathrm{~kW}$ and $3 \mathrm{~kW}$, respectively. It seems that these power generation densities were obviously larger than that $\left(\sim 150 \mathrm{~W} / \mathrm{m}^{2}\right)$ of commercial solar plates. However, using the 
internal area of the heat collector $\left(0.151 \mathrm{~m}^{2}\right)$ to calculate the power generation density led to new values of $57 \mathrm{~W} / \mathrm{m}^{2}, 162 \mathrm{~W} / \mathrm{m}^{2}$, and $241 \mathrm{~W} / \mathrm{m}^{2}$, respectively. As a consequence, these power generation densities turned to be comparable to that of solar plates. Nevertheless, TEG could be the most promising technology to convert waste heat into electricity in distributed small-scale engines, such as engines in passenger vehicles and inland vessels. The major reasons include its compactness and solid-state energy-conversion process, which are essentially required, as space is limited in the abovementioned energy systems.
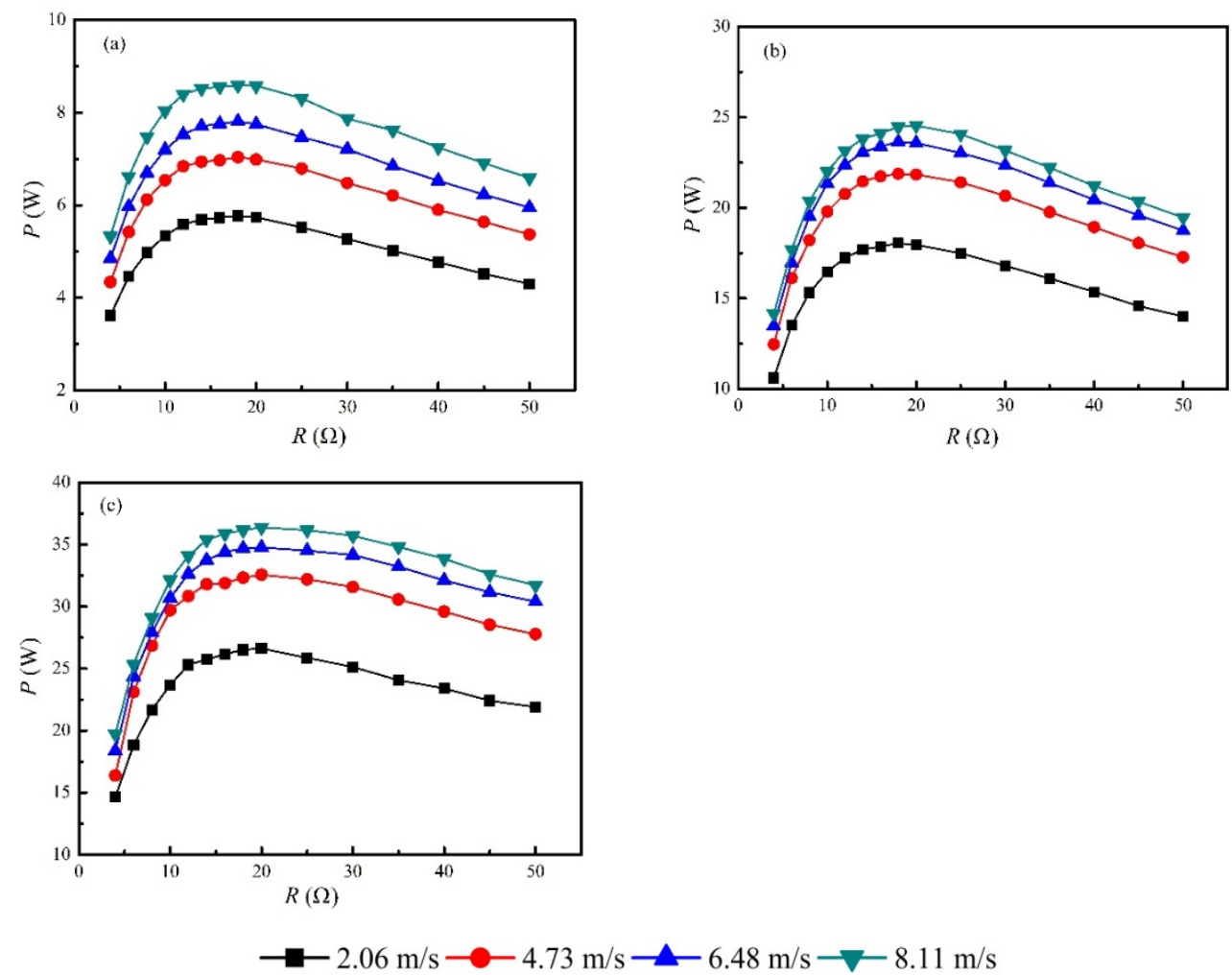

Figure 5. Power load feature of total electric power under various heating powers and air velocities. (a) $P_{\text {in }}=1 \mathrm{~kW}$. (b) $P_{\text {in }}=2 \mathrm{~kW}$. (c) $P_{\text {in }}=3 \mathrm{~kW}$.

\subsection{Efficiency}

As mentioned above, one of the essential issues in applying TEG technology in utilizing waste heat is the performance of the heat collector. Therefore, it is important to discuss the heat collection efficiency of the present TEG, which is shown in Figure 6. In the present work, no insulation was applied to the heat collector. As a result, a certain amount of heat flux extracted from the heated air by the heat collector was dissipated to the surroundings through natural convections and thermal radiations. Therefore, only part of the heat passed through the TE modules.

As shown in Figure 6, the average heat collection efficiency according to Equation (1) was $46.5 \%$, and the average effective heat collection efficiency decreased to $36.6 \%$, according to Equation (3). This was consistent with previous works, i.e., 32.9\% in Kim's work [8]. Increasing fin density could help to improve the heat collection efficiency, but it is subject to the pressure loss problem. Increasing the length of the heat collector could be another way to augment the heat collection efficiency. However, as shown in Figure 4, the temperature differences for Group-3 and Group-4 were obviously lower than those of Group-1 and Group-2. Therefore, the temperature difference will become even smaller as the length of the heat collector increases. As a consequence, minor improvements can be obtained when increasing the length of the heat collector. 


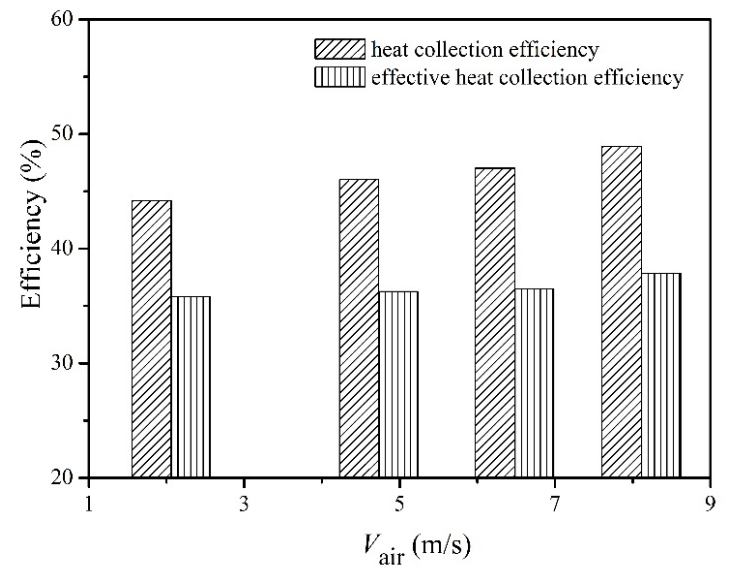

Figure 6. Heat collection efficiency when the heating power was $3 \mathrm{~kW}$.

The measured TE efficiency according to Equation (4) can be used to reveal the effectiveness of TE modules, which should be close to the theoretically predicted result according to Equations (7) and (8). The experimental TE efficiency, the predicted TE efficiency and the overall efficiency are shown in Figure 7 . The average measured TE efficiency was $2.88 \%$, whereas the predicted TE efficiency was $3.38 \%$, which was based on the temperaturedependent properties of the TE materials. Many parameters, including hot/cold-end temperatures, electric power, the convective heat transfer coefficient, thermal contact ratio, and the electrical resistivity ratio and wiring method of the TEG, affect the consistency between the measured TE efficiency and theoretical prediction. The wiring method could be a major reason for the abovementioned difference in TE efficiency. As shown in Figure 4, the temperature differences were different in different groups of TE modules, indicating that a certain amount of electric power was lost when wiring the TE modules in parallel, which was demonstrated in previous works [20]. The maximum overall efficiency was $1.21 \%$ at the air velocity of $8.11 \mathrm{~m} / \mathrm{s}$ when the heating power was set at $3 \mathrm{~kW}$. Based on above analysis, two important parameters were revealed to be essential when applying TEG technology to recover waste heat, i.e., heat collection efficiency and TE efficiency. As mentioned in Equation (8), the TE efficiency was determined by the physical properties of the TE materials, which relies on the innovation of new TE materials [1]. Otherwise, multi-stage TE modules [21] and combined photovoltaic-thermoelectric generation [22] were possible methods to increase the overall efficiency. Note that the abovementioned overall efficiency does not take the electric power consumption of the water pump and blower into consideration, due to the fact that the cooling systems differed from each other in real applications. In the present work, a total electric power of $10.6 \mathrm{~W}$ was consumed by the water pump and blowers.
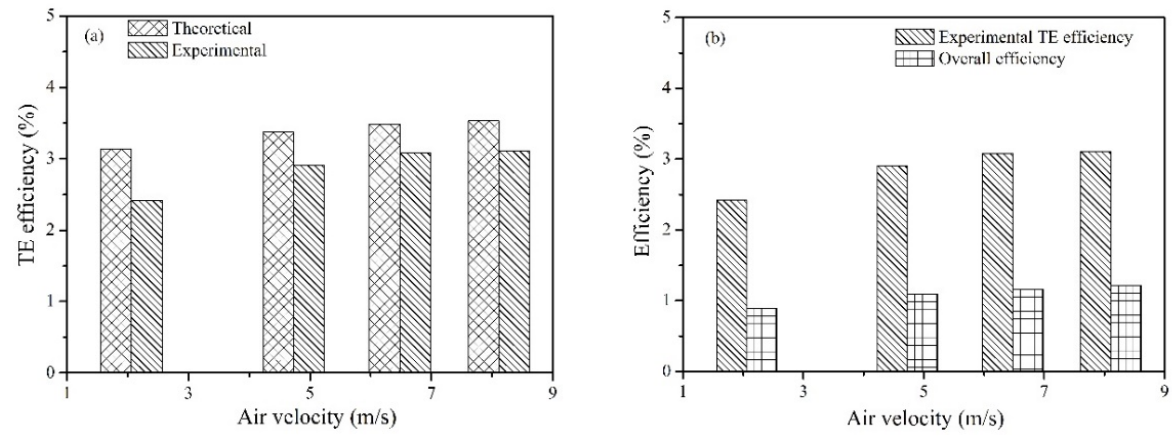

Figure 7. Conversion efficiencies when the heating power was $3 \mathrm{~kW}$; (a) comparison between theoretical TE efficiencies and experimental results; (b) comparison of TE efficiencies and overall efficiencies. 


\subsection{Influence of MPPT Technology on Electricity Output}

In real applications, a battery has to be employed to balance the power generation and electric output. Therefore, a DDC has to be used. Though MPPT DDCs are suggested in many references [23], a direct comparison between MPPT DDC and regular DDC is still lacking, specially presenting their charging curves into batteries. Figure 8 shows the experimental measured performances of two regular DDCs and a MPPT DDC. The internal resistance of the battery varies with time; therefore, the maximum electric power $(36.4 \mathrm{~W})$ cannot be reached. As shown in Figure 8, the MPPT DDC performs better than regular DDCs. The average charging power into the battery in the first 60 minutes was $33.2 \mathrm{~W}$ for the MPPT DDC, whereas the average charging powers were $28.8 \mathrm{~W}$ and $28.2 \mathrm{~W}$ for DDC-1 and DDC-2, respectively. This implied that an improvement of $15.3 \%$ was achieved, which was consistent with a previous work, i.e., $14.5 \%$ of improvement reported in Yu and Chau's work [24]. After 80 min of charging, the battery accepted less electric power, and the charging power dropped to a lower value for MPPT DDC, whereas the charging powers for regular DDCs maintained unchanged, because the total amount of charged electric power was less than that with MPPT DDC. In other words, the shorter time needed to reach a saturated charging mode denoted a higher conversion efficiency of the DDC. The conversion efficiency for MPPT DDC was $91.2 \%$, whereas the average conversion efficiencies were $79.2 \%$ and $77.5 \%$ for DDC- 1 and DDC-2, respectively, which was consistent with our previous works [25]. Therefore, MPPT DDC is recommended in future studies.

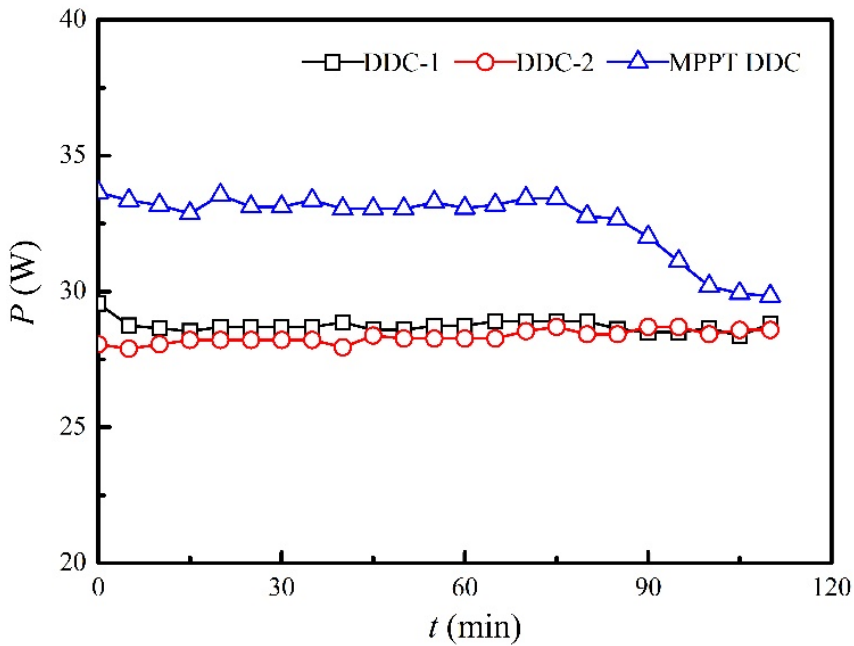

Figure 8. Comparison of charging power between regular DDCs and the MPPT DDC when the heating power and air velocity were set at $3 \mathrm{~kW}$ and at $8.11 \mathrm{~m} / \mathrm{s}$, respectively.

\subsection{Pressure Drop}

In field applications, pressure drop has to be considered combining with the heat collector performance. In the case of adding a heat collector downstream of the exit of the waste heat resource, too large a pressure drop will cause failure in the upstream equipment. The pressure drop is directly linked to the gas velocity and the fin design. The measured pressure drop of the present heat collector is shown in Figure 9. Heating power had a minor influence on the pressure drop, which is not shown in Figure 9. The maximum pressure drop was $36 \mathrm{~Pa}$, and it decreased further as the air velocity became smaller. This pressure drop was much smaller than previous studies, i.e., 10,000 $\mathrm{Pa}$ in $\mathrm{Li}^{\prime}$ 's work [7], 400-2000 Pa in Kim's work [8], and 380 Pa in Kim's work [6]. Table 1 presents a comparison between the results in this work and previous reports. The moderate heat collection efficiency of $46.5 \%$ and the notably low-pressure drop of $36 \mathrm{~Pa}$ were achieved through proper fin design and the integrity of the heat collector. The trade-off between the heat collection and the pressure drop could be achieved by considering the following 
aspects. (1) Dense fins on targeted surfaces. In the present work, four fins were designed in the surfaces where TE modules were installed, whereas the other two surfaces only had two fins. (2) A heat collector with an integrated molding design. The integrity of the aluminum tube in this work could transfer heat to the TE modules from every part of the heat collector, because the thermal conductivity $\left(\sim 180 \mathrm{~W} / \mathrm{m}^{2}-\mathrm{K}\right)$ was much higher than that of TE modules $\left(\sim 1.5 \mathrm{~W} / \mathrm{m}^{2}-\mathrm{K}\right)$. (3) A built-in by-pass channel inside the heat collector. The central part of the heat collector in the present work, with a diameter of $40 \mathrm{~mm}$, was kept empty without any fins, helping to decrease the pressure drop. In future works, certain disturbers could be placed alternately in this empty space to disturb the thermal boundary layers of the fins, so as to increase the heat collection efficiency. Besides, designing pin-fins inside the heat collector and separating flue gases to multiple streams are possible directions to improve heat collector performance.

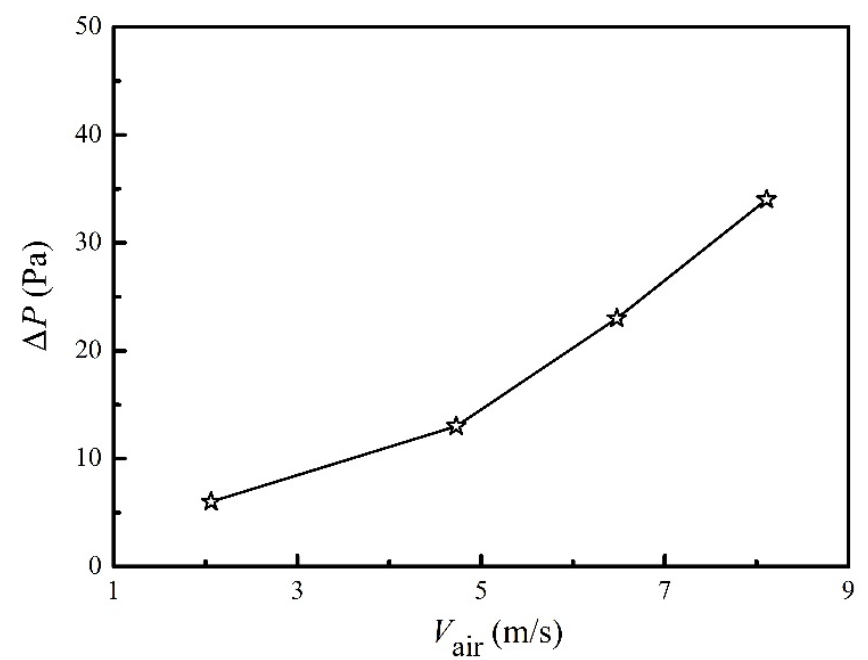

Figure 9. Pressure drops at different air velocities when the heating power was $3 \mathrm{~kW}$.

Table 1. Performance comparisons with various previous studies.

\begin{tabular}{cccc}
\hline Reference & Overall Efficiency (\%) & Heat Collection Efficiency (\%) & Pressure Drop (Pa) \\
\hline Kim, Negash and Cho (2017) [6] & $1.4-2.0$ & $-{ }^{*}$ & 380 \\
Li et al. (2017) [7] & $0.8 \sim 1.2$ & - & $2000 \sim 10,000$ \\
Kim, Kwak and Kim (2018) [8] & $1.3 \sim 2.6$ & 32.9 & $400 \sim 2000$ \\
Comamala et al. (2019) [26] & 1.08 & - & 5400 \\
present & 1.21 & 46.5 & 36 \\
\hline
\end{tabular}

* Denotes unknown or not reported.

\section{Conclusions}

A lab-scale thermoelectric generator (TEG) utilizing waste heat from flue gases of passenger vehicles was designed and tested to study the heat collection efficiency, thermoelectric efficiency, overall efficiency, and electric power extracting efficiency under the condition of a sufficient low-pressure drop. The following conclusions can be drawn based on above analysis:

(1) The integrated molding design of heat collector with appropriate fin distribution was proven to be able to achieve a considerably low-pressure drop, while keeping a relatively high heat-collection efficiency. In the present TEG prototype, the pressure drop was $36 \mathrm{~Pa}$, which is much lower than those of previous studies. Meanwhile, the heat collection efficiency of $46.5 \%$ was comparable with previous works;

(2) The overall efficiency of the TEG system was relatively low (1.21\% in maximum), which was determined by the heat collection efficiency and the thermoelectric efficiency. The experimental thermoelectric efficiency was $2.88 \%$, which was close to the predicted value of $3.38 \%$. Essential issues when applying TEG to recover waste heat include optimizing the heat collector and TE materials; 
(3) Maximum power point tracking (MPPT) direct current-direct current converters (DDC) should be used because they performed much better than regular converters. In the present work, the conversion efficiency of the MPPT DDC was $91.2 \%$, whereas the average conversion efficiency was lower than $80 \%$ for regular DDCs.

(4) The insufficient heat transfer nature between flue gases and the solid-heat collector must be improved in the future work. As revealed in the present work, the average hot-end temperatures were $46.9 \%$ lower than the inlet flue gas temperatures. This reduced the application potential of TEG for utilizing waste heat from passenger vehicles. Thermosyphon, staggered pin-fins and appropriate flow perturbations are possible research directions.

Author Contributions: Conceptualization, J.C. and G.L.; methodology, W.X. and G.L.; software, M.D.; validation, G.L. and Y.T.; investigation, G.S.; writing —original draft preparation, J.C. and G.L.; writing—review and editing, G.L.; project administration, J.C. and W.X.; funding acquisition, G.L. All authors have read and agreed to the published version of the manuscript.

Funding: This work was supported by the Natural Science Foundation of Zhejiang Province (Grant no. LZ21E060001, LQ21E060001), the key R\&D plan of Zhejiang Province (Grant no. 2020C03115), and the Fundamental Research Funds of ZUST (2020-CXCY002).

Data Availability Statement: The data presented in this study are available on request from the corresponding author.

Conflicts of Interest: We declare that we have no financial and personal relationship with other people or organizations that can inappropriately influence our work, there is no professional or other personal interest of any nature or kind in any product, service and/or company that could be construed as influencing the position presented in, or the review of, the manuscript entitled "Experiments on thermoelectric generation utilizing waste heat from passenger vehicles".

\section{Nomenclature}

$k$ thermal conductivity $(\mathrm{W} / \mathrm{m}-\mathrm{K})$

$L \quad$ length of the TE leg $(\mathrm{m})$

$n \quad$ electrical resistivity ratio $(\mathrm{m})$

$P \quad$ load power (W)

$Q_{\text {conv }}$ heat loss rate by convections (W)

$Q_{\mathrm{HC}} \quad$ heat flow rate extracted by heat collector $(\mathrm{W})$

$P_{\text {in }} \quad$ heating power $(\mathrm{W})$

$P_{\max } \quad$ maximum electric power generated by the TEG system (W)

$Q_{\text {rad }} \quad$ heat loss rate by thermal radiations (W)

$Q_{\mathrm{TE}} \quad$ heat flow rate passing through the TE modules (W)

$\triangle P \quad$ pressure drop $(\mathrm{Pa})$

$r \quad$ thermal contact ratio (dimensionless)

$R \quad$ load resistance $(\Omega)$

$T_{\text {ave }} \quad$ average temperature of hot and cold ends $\left({ }^{\circ} \mathrm{C}\right), T_{\text {ave }}=\left(T_{\mathrm{h}}+T_{\mathrm{c}}\right) / 2$

$t \quad$ time (minute)

$T_{\mathrm{C}} \quad$ cold-end temperature $\left({ }^{\circ} \mathrm{C}\right)$

$T_{\mathrm{h}} \quad$ hot-end temperature $\left({ }^{\circ} \mathrm{C}\right)$

$T_{\text {in }} \quad$ inlet air temperature $\left({ }^{\circ} \mathrm{C}\right)$

$T_{\mathrm{w}, \text { in }} \quad$ inlet cooling water temperature $\left({ }^{\circ} \mathrm{C}\right)$

$T_{\mathrm{w} \text {,out }}$ outlet cooling water temperature $\left({ }^{\circ} \mathrm{C}\right)$

$\Delta T$ temperature difference $\left({ }^{\circ} \mathrm{C}\right), \Delta T=T_{\mathrm{h}}-T \mathrm{c}$

$V_{\text {air }} \quad$ air velocity $(\mathrm{m} / \mathrm{s})$

$w \quad$ ratio of ceramic thickness to the length of TE leg (dimensionless)

$\mathrm{Z} \quad$ figure-of-merit $(1 / \mathrm{K})$

$\alpha \quad$ Seebeck coefficient $(\mathrm{V} / \mathrm{K})$ 


\section{Nomenclature}

$\begin{array}{ll}\rho & \text { electrical resistivity }(\Omega \mathrm{m}) \\ \eta_{\text {heat }} & \text { heat collection efficiency }(\%) \\ \eta_{\text {heat,eff }} & \text { effective heat collection efficiency (\%) } \\ \eta_{\text {sys }} & \text { overall efficiency }(\%) \\ \eta_{\text {TE }} & \text { TE efficiency }(\%)\end{array}$

$\begin{array}{ll}\text { Abbreviations } \\ \text { DAQ } & \text { data acquisition } \\ \text { DDC } & \text { DC-DC converter } \\ \text { MPPT } & \text { maximum power point tracking } \\ \text { TE } & \text { thermoelectric } \\ \text { TEG } & \text { TE generator }\end{array}$

\section{References}

1. Zhao, L.-D.; Lo, S.-H.; Zhang, Y.S.; Sun, H.; Tan, G.H.; Uher, C.; Wolverton, C.M.; Dravid, V.P.; Kanatzidis, M.G. Ultralow thermal conductivity and high thermoelectric figure of merit in SnSe crystals. Nature 2014, 508, 373-377. [CrossRef]

2. Zhao, L.-D.; Tan, G.; Hao, S.; He, J.; Pei, Y.; Chi, H.; Wang, H.; Gong, S.; Xu, H.; Dravid, V.P.; et al. Ultrahigh power factor and thermoelectric performance in hole-doped single-crystal SnSe. Science 2016, 351, 141-144. [CrossRef]

3. Champier, D. Thermoelectric generators: A review of applications. Energy Convers. Manag. 2017, 140, 167-181. [CrossRef]

4. Remeli, M.F.; Date, A.; Orr, B.; Ding, L.C.; Singh, B.; Affandi, N.D.N.; Akbarzadeh, A. Experimental investigation of combined heat recovery and power generation using a heat pipe assisted thermoelectric generator system. Energy Convers. Manag. 2016, 111, 147-157. [CrossRef]

5. Junior, O.A.; Maran, A.L.O.; Henao, N.C. A review of the development and applications of thermoelectric microgenerators for energy harvesting. Renew. Sustain. Energy Rev. 2018, 91, 376-393. [CrossRef]

6. Kim, T.Y.; Negash, A.; Cho, G. Direct contact thermoelectric generator (DCTEG): A concept for removing the contact resistance between thermoelectric modules and heat source. Energy Convers. Manag. 2017, 142, 20-27. [CrossRef]

7. Li, Y.; Wang, S.; ZhAO, Y.; Lu, C. Experimental study on the influence of porous foam metal filled in the core flow region on the performance of thermoelectric generators. Appl. Energy 2017, 207, 634-642. [CrossRef]

8. Kim, T.Y.; Kwak, J.; Kim, B.-W. Energy harvesting performance of hexagonal shaped thermoelectric generator for passenger vehicle applications: An experimental approach. Energy Convers. Manag. 2018, 160, 14-21. [CrossRef]

9. Lan, S.; Yang, Z.; Chen, R.; Stobart, R. A dynamic model for thermoelectric generator applied to vehicle waste heat recovery. Appl. Energy 2018, 210, 327-338. [CrossRef]

10. Massaguer, A.; Comamala, M.; Pujol, T.; González, J.; Cardenas, M.; Carbonell, D.; Bueno, A. A method to assess the fuel economy of automotive thermoelectric generators. Appl. Energy 2018, 222, 42-58. [CrossRef]

11. Zhao, Y.; Wang, S.; Ge, M.; Li, Y.; Yang, Y. Energy and exergy analysis of thermoelectric generator system with humidified flue gas. Energy Convers. Manag. 2018, 156, 140-149. [CrossRef]

12. Eddine, A.N.; Chalet, D.; Faure, X.; Aixala, L.; Chessé, P. Optimization and characterization of a thermoelectric generator prototype for marine engine application. Energy 2018, 143, 682-695. [CrossRef]

13. Zhao, Y.; Wang, S.; Ge, M.; Liang, Z.; Liang, Y.; Li, Y. Performance analysis of automobile exhaust thermoelectric generator system with media fluid. Energy Convers. Manag. 2018, 171, 427-437. [CrossRef]

14. Marvão, A.; Coelho, P.J.; Rodrigues, H. Optimization of a thermoelectric generator for heavy-duty vehicles. Energy Convers. Manag. 2019, 179, 178-191. [CrossRef]

15. Tang, S.; Wang, C.; Liu, X.; Su, G.; Tian, W.; Qiu, S.; Zhang, Q.; Liu, R.; Bai, S. Experimental investigation of a novel heat pipe thermoelectric generator for waste heat recovery and electricity generation. Int. J. Energy Res. 2020, 44, 7450-7463. [CrossRef]

16. Brito, F.; Pacheco, N.; Vieira, R.; Martins, J.; Teixeira, J.; Goncalves, L.; Oliveira, J.; Hall, M. Efficiency improvement of vehicles using temperature controlled exhaust thermoelectric generators. Energy Convers. Manag. 2020, 203, 112255. [CrossRef]

17. Rowe, D.M. CRC Handbook of Thermoelectrics; CRC Press: London, UK, 1998.

18. Rowe, D.; Min, G. Evaluation of thermoelectric modules for power generation. J. Power Sources 1998, 73, 193-198. [CrossRef]

19. Gu, J.; Han, D.; Zheng, M.; Si, Z.; Chen, J. Design and experiments of a thermoelectric generator coupled to a gas cooker with energy storage module and thermosyphon cooling system. Energy Sources Part A Recovery Util. Environ. Eff. 2020, 28, 1-19. [CrossRef]

20. Liu, Y.-H.; Chiu, Y.-H.; Huang, J.-W.; Wang, S.-C. A novel maximum power point tracker for thermoelectric generation system. Renew. Energy 2016, 97, 306-318. [CrossRef]

21. Zhou, M.; He, Y.; Chen, Y. Three-dimensional numerical modeling and characterization of two-stage and multilayer thermoelectric couples. Int. J. Green Energy 2016, 13, 736-746. [CrossRef] 
22. Lekbir, A.; Meddad, M.; Benhadouga, S.; Khenfer, R. Higher-efficiency for combined photovoltaic-thermoelectric solar power generation. Int. J. Green Energy 2019, 16, 371-377. [CrossRef]

23. Kermadi, M.; Berkouk, E.M. Artificial intelligence-based maximum power point tracking controllers for Photovoltaic systems: Comparative study. Renew. Sustain. Energy Rev. 2017, 69, 369-386. [CrossRef]

24. Yu, C.; Chau, K.T. Thermoelectric automotive waste heat energy recovery using maximum power point tracking. Energy Convers. Manag. 2009, 50, 1506-1512. [CrossRef]

25. Li, G.N.; Zhang, S.; Zheng, Y.Q.; Zhu, L.Y.; Guo, W.W. Experimental study on a stove-powered thermoelectric generator (STEG) with self starting fan cooling. Renew. Energy 2018, 121, 502-512. [CrossRef]

26. Comamala, M.; Massaguer, A.; Pujol, T. Validation of a fuel economy prediction method based on thermoelectric energy recovery for mid-size vehicles. Appl. Therm. Eng. 2019, 153, 768-778. [CrossRef] 